\title{
建筑工程施工绿色施工技术应用管理研究
}

于成浩

天津天一建设集团有限公司

DOI: $10.18686 /$ bd.v1i11.1062

[摘要] 随着中国经济的快速发展, 建筑业蓬勃发展。现代建筑业在建设过程中主要提出绿色建筑的概念, 重视环境保 护, 节能减排, 减少能源消耗, 最终实现可持续发展战略。因此, 绿色建筑和相应的绿色建筑得到了广泛的重视和推广。绿色 施工技术主要是通过技术手段减少环境污染, 降低建筑能耗, 实现建筑业的可持续发展和建筑业的振兴。本文论述了绿色 施工技术在建筑工程中的应用管理分析。

[关键词] 建筑工程; 绿色施工技术; 应用; 管理

\section{1 绿色施工技术的含义与特点}

建筑业的快速发展是经济发展的结果。是国民经济的 重要支撑,也是消耗大量自然资源的行业之一。如果施工控 制不好,施工技术会对环境造成负面影响。绿色施工是指在 全面实施绿色施工规划和实施资源可持续发展战略的周期 性建设过程中建设。同时利用高新技术降低施工对环境造 成的污染, 采用科学的施工方法和高效施工, 减少施工带来 的施工污染等负面影响, 是我国节约资源和保护环境的重 要技术。绿色施工技术是一项宝贵的建筑施工技术, 施工技 术的高效利用, 已经成为建筑施工企业具有较强竞争力的 核心技术。当然, 绿色施工技术的建设比其他施工技术先 进, 深受广大施工单位的喜爱: 施工原则是以环境保护为主 要建设目的, 为了保护地球资源和高效利用以有效资源为 核心, 在建设维护建设和社会和谐, 维护人与自然和谐为目 标的过程中。世界调查认为, 绿色建筑大大提高了人们的工 作效率, 包括财务回报和居民的幸福指数。总的来说, 绿色 施工技术具有广泛而清晰的特点, 即在资源可持续利用的 基础上, 满足所有施工, 在保证施工质量和施工安全的条件 下, 最大限度地保护生态环境, 实现人类伟大建筑技术的综 合目标。

\section{2 建筑工程施工绿色施工技术应用}

2.1 采取措施减少对土地的占用

施工规模和现场条件是选择临时用材加工厂，防雨遮 阳棚, 现场堆放场地, 办公用房用地等临时设施必须考虑的 两个因素。必须规划和设计占用土地, 以满足占用土地面积 的最低要求。这些房屋的布置尽可能合理, 紧凑, 满足施工 要求, 减少死亡空间和未利用地。这里提到的施工要求意味 着环境和施工作业对人体的危害最小。建设安全文明。办公 室和生活空间布局最大限度地减少对周围环境的影响, 并 且在施工现场可以轻松调整, 以适应光钢板房, 钢板房等标 准组装式结构的条件。施工场地要坚起一堵墙, 让不相干的 人不能进来避免伤害他们, 还要避免乱放垃圾, 影响居民的 出行和生活。

2.2 绿色建筑材料采购
绿色建筑材料是符合建筑设计期间选定的绿色建筑标 准的建筑材料。严格控制建筑材料主要材料放射性元素和 各种有害物质(气体)指标体系。并且必须确保施工过程中 使用的其他辅助材料符合绿色施工标准, 如水溶性涂料的 选择, 避免使用溶剂型涂料等。这从购买建材开始, 严格控 制绿色建材的使用。

\section{3 扬尘污染控制措施}

2.3.1 散装水泥管在喂料时极易产生扬尘, 然后对空气 造成污染, 为此我们采取措施向另一个出水口加一根软管, 准备一个 $40 \mathrm{~kg}$ 水泥桶充满水, 让软管一端出口的水泥桶 中, 一个变成了水泥桶的底部, 水泥在送人空气时留在桶 中, 所以水泥与空气一起排出, 经过水过滤管, 虽然不能完 全控制灰尘,但可以大大减少空气污染。关于人造材料的排 放方法我们使用水泥桶下部的空心砖块, 只留下排放位置, 在排料口放一个麻袋, 当麻料口直接放在车内的时候, 发 射。

2.3.2 控制道路扬尘: 对施工道路及时进行硬化, 利用 收集井水和自流深井的地下水合理利用及时冲洗道路。

2.3.3 控制瓷砖、花岗岩切割时产生的粉尘: 切割瓷砖、 花岗岩应采用简单实用的水割法, 其一能对切割片降温延 长切割片的寿命, 其二控制由此产生的粉尘, 水割法具有良 好的效果。

2.4 建筑废弃物回收利用

在绿色建筑建设中除了绿色建材还要重视建筑垃圾! 废弃物的回收利用在传统建筑中, 施工垃圾被废弃, 大量的 土地被打桩或填埋, 这不仅造成资源浪费, 而且污染环境, 对环境造成很大影响, 包括施工的浸出废弃物进人土壤和 水层污染土壤和地下水有机物分解发生有毒气体, 同时空 气污染忽视了建筑垃圾的再利用会浪费大量的资源, 所以 要注意建筑垃圾的回收利用, 将涉及节能, 节材, 土地和环 境保护的可持续性和综合性问题 “绿色建筑把建筑垃圾作 为可回收和利用的建筑副产品, 如将废木材转化为造纸原 料, 燃料, 堆肥, 绿化等木材回收机器。在混合废物处理厂将 混合废物 (玻璃,纸张, 塑料,金属)分离和回收利用。 
2.5 优化垃圾处理技术

建筑节能的一个重要方面就是从源头上减少施工过程 中的各种垃圾。对于运出市场的各类建筑垃圾, 垃圾进行分 类分类,可循环利用的原材料可循环使用。在建材初选时, 要进行详细的分析研究,选择新型节能建材。垃圾处理技术 的优化主要是从建筑废料的选择, 垃圾已经产生的分类分 类。可用回收,不可重复使用,进行绿色处理。

\section{6 新技术及新材料应用}

优化施工工艺, 提高高性能材料的应用,不仅可以提高 施工效率, 加快施工进度, 而且可以节约资源, 减少环境负 荷。例如在高层深基坑施工中可采用反时相法,地下室一楼 的地下室结构完成后, 地下部分的施工可以在一个密闭的 地下空间内完成,可以减少开放深基坑施工区的噪声,粉尘 等环境影响。在城市地下管线施工, 更换和维护中, 采用非 开挖埋管技术不会破坏基础设施,影响城市交通,具有施工 进度快,资源消耗低,环境污染小,综合效益。在桩基础工程 中可用静水压施工锤击施工方法代替。采用高性能混凝土 技术, 如淡水混凝土, 表面不能抹灰, 喷涂, 悬挂等装饰装 修,可节约资源, 减少和避免垃圾和噪音的产生;采用无振 挂击混凝土, 实现高流量特性, 不仅可以减少混凝土浇筑 量, 而且还可以避免振动时产生的噪音, 降低了工人的劳动 强度。在大直径钢与直螺纹机械连接的连接中, 可减少焊接 中的光污染和功耗。采用大模板, 滑模等新模板, 还可以减 少钢网模板安装的组合, 去除噪音等。加强信息技术应用, 如 $\mathrm{CAD}$ (计算机辅助设计), $\mathrm{CAC}$ (计算机辅助施工)技术和 基于 Web 的协同施工技术在建筑物的建设。推进计算机模 拟分析,发展新的管理运作模式, 推动传统施工管理模式向 数字化建设管理模式的转变。利用信息技术,精心施工和优 化整合等方式,完成绿色建筑施工所需指标。

\section{3 施工现场的绿色管理}

3.1 扬尘的绿色环保化处理。如果施工现场的灰尘问题 比较严重,会给环境带来更严重的污染。一般来说, 粉尘治 理主要采取以下措施：一是可以在施工现场正确安装酒水 装置,保证施工场地的清洁。但是不应该使用自来水等水源 来避免浪费水资源。其次,施工出现土方时, 应集中放置, 并 覆盖薄膜, 以防止灰尘的出现。如果地表暴露在土方所在地 区, 则应将土壤环境与矮化植物的种植结合起来。当土方运 输时,灰尘,在身体上使用屏蔽措施。此外,您也可以尝试使 用特殊的管道或设备运输建筑垃圾。

3.2 固体废弃物的绿色环保化处理。在施工过程中不可 避免地会产生固体废物, 一般的处理措施是直接运到城市
附近的大型垃圾处理厂。但从整体城市环境来看, 还有潜在 的环境污染问题需要改进。通常情况下,固体废物应该集中 优先考虑。如果在施工期间需挖掘土石方,应及时回填。

3.3 废气的排放。对于废气的处理, 减排量应继续优化, 一方面要严格要求车辆及相关设备, 机械排放的建设, 采取 适当的控制措施。另一方面,如果施工现场位于城市中心或 其他重要区域，则不应使用产生大量废气的木材等材料进 行消防。另外,施工焊接等施工还应配备适当的专业处理设 备,避免废气中含有大量粉尘。

3.4 噪音污染管理。施工场地施工噪声, 同样会对周边 环境产生影响,进一步影响周边居民生活。一方面要配备好 隔声设备, 在关键区域设置噪声监测点, 动态监测。如有噪 音超标, 应按施工条件及时采取措施。另一方面, 如果施工 处于夜间环境,则更需要妥善管理噪声。先进的低噪声机械 设施应根据施工需要进行选择, 并定期维护。使用设备时, 应提供隔音屏障。另外, 混凝土浇筑和木板房建筑,需要采 取适当的噪音处理措施。

3.5 资源节约化管理。一方面, 在实际建设过程中, 要注 意减少能源损失, 尽可能利用高效率, 低能耗的机械设备, 提高电力, 石油, 天然气等能源的利用率优化施工设备能耗 结构, 主动采用优质可再生能源, 采取严格的施工能耗控制 措施; 应该结合该地区的建筑面积, 调整施工技术和工艺, 尽可能使用新材料,物料运输和应用, 以减少消耗。另一方 面, 要切实提高资源的有效利用率, 严格控制建设用能, 确 保资源有效利用总体上有所提高, 采取监测措施, 加强能源 管理。

总而言之,随着社会, 经济和科技的不断发展和创新, 人们对生活水平和生活环境的要求也在不断提高。但是社 会经济建设造成的严重环境污染问题违背了人们的要求各 种环境和资源问题一直困扰着人类，严重制约了人类社会 的进一步发展。绿色建筑理念的产生和发展, 是为了解决环 境污染与社会和谐发展之间的矛盾。从尊重生态系统的客 观规律出发, 将成为建筑业发展的新趋势, 必将得到人们的 关注。

\section{参考文献:}

[1]谭红建. 探析绿色施工技术在房建工程中的运用 [J].绿色环保建材,2017,(10):155.

[2]占美森.建筑施工绿色施工技术应用对策[J].江西 建材,2017,(12):108-109.

[3]施海云.绿色施工管理理念下的创新建筑施工管理 探讨[J].住宅与房地产,2017,(06):169+213. 